\title{
Tiotropium/Olodaterol: A Review in COPD
}

\author{
Hannah A. Blair ${ }^{1}$ \\ Published online: 22 May 2019 \\ (c) Springer Nature 2019, corrected publication 2019
}

\begin{abstract}
Tiotropium/olodaterol (Stiolto ${ }^{\circledR}$ Respimat $^{\circledR}$; Spiolto ${ }^{\circledR}$ Respimat $^{\circledR}$ ) is an inhaled fixed-dose combination of the long-acting muscarinic antagonist tiotropium bromide (hereafter referred to as tiotropium) and the long-acting $\beta_{2}$-adrenergic agonist olodaterol. It is available in several countries, including the USA, Japan, China and those of the EU, where it is indicated for the long-term maintenance treatment of patients with chronic obstructive pulmonary disease (COPD). The efficacy of tiotropium/olodaterol 5/5 $\mu \mathrm{g} /$ day in patients with COPD was evaluated in phase III or IV trials of 6-52 weeks' duration. Tiotropium/olodaterol improved lung function to a greater extent than each of its individual components or placebo in 12- and 52-week trials. In 6-week trials, tiotropium/olodaterol provided greater lung function benefits over $24 \mathrm{~h}$ than the individual components, placebo or twice-daily fluticasone propionate/salmeterol. Tiotropium/olodaterol also demonstrated beneficial effects on health-related quality of life (HR-QoL), dyspnoea, inspiratory capacity, exercise endurance and the need for rescue medication. In an 8-week open-label trial, umeclidinium/vilanterol was superior to tiotropium/olodaterol for the primary endpoint of trough forced expiratory volume in $1 \mathrm{~s}$. The tolerability profile of tiotropium/olodaterol was generally similar to that of the individual components. In conclusion, tiotropium/olodaterol provides a useful option for the maintenance treatment of COPD, with the convenience of once-daily administration via a single inhaler.
\end{abstract}

\section{Tiotropium/olodaterol: clinical considerations in} COPD

Improves lung function to a greater extent than the individual components

Has beneficial effects on HR-QoL, dyspnoea, inspiratory capacity, exercise endurance and need for rescue medication

Tolerability profile generally similar to that of the individual components
The manuscript was reviewed by: $\boldsymbol{S}$. A. Antoniu, Department of Medicine II, 'Grigore T. Popa' University of Medicine and Pharmacy, Iasi, Romania; E. Derom, Department of Respiratory Medicine, Ghent University Hospital, Ghent, Belgium;

C. Incorvaia, Cardiac and Pulmonary Rehabilitation Unit, ICP Hospital, Milan, Italy.

Hannah A. Blair

demail@springer.com

1 Springer Nature, Private Bag 65901, Mairangi Bay, Auckland 0754, New Zealand

\section{Introduction}

Chronic obstructive pulmonary disease (COPD) is characterized by persistent respiratory symptoms (e.g. dyspnoea, cough, sputum production) and airflow limitation [1]. Several pharmacological agents are available for the treatment of COPD, including bronchodilators (e.g. $\beta_{2}$-adrenergic agonists, anticholinergics, methylxanthines), inhaled corticosteroids (ICS), phosphodiesterase-4 inhibitors and mucolytic agents. Maintenance bronchodilator therapy is key to the management of stable COPD, which aims to reduce symptoms and the frequency and severity of exacerbations, while improving health-related quality of life (HR-QoL) and exercise tolerance. Oral inhalation is the preferred route of administration, with long-acting formulations preferred over short-acting agents. Combining two bronchodilators with different durations and mechanisms of action may increase the degree of bronchodilation and reduce the risk of adverse events compared with the individual components, providing a rationale for the development of fixeddose combinations [1].

Tiotropium/olodaterol (Stiolto ${ }^{\circledR}$ Respimat $^{\circledR}$; Spiolto ${ }^{\circledR}$ Respimat $^{\circledR}$ ) is a fixed-dose combination of the long-acting muscarinic antagonist (LAMA) tiotropium 
bromide (hereafter referred to as tiotropium) and the longacting $\beta_{2}$-adrenergic agonist (LABA) olodaterol, delivered via the Respimat ${ }^{\circledR}$ soft mist inhaler (SMI). It is approved in several countries, including the USA [2], Japan [3], China [4] and those of the EU [5], for the long-term maintenance treatment of COPD. The pharmacological properties of tiotropium and olodaterol are well known, have been previously reviewed in detail [6-8] and are summarized in Table 1. This article focuses on the clinical use of tiotropium/olodaterol in patients with COPD.

\section{Therapeutic Efficacy of Tiotropium/ Olodaterol}

\subsection{TOviTO Clinical Trial Programme}

The efficacy of inhaled tiotropium/olodaterol in patients with COPD was investigated in the TOviTO clinical trial programme. Although most trials evaluated two dosages of tiotropium/olodaterol (2.5/5 and 5/5 $\mu \mathrm{g}$ once daily), discussion here focuses on the approved dosage of $5 / 5 \mu \mathrm{g} /$ day.

The effects of tiotropium/olodaterol on lung function and/or HR-QoL were evaluated in several randomized, double-blind, multinational, phase III trials, including the

Table 1 Overview of key pharmacological properties of inhaled tiotropium and olodaterol [6-8]

Pharmacodynamic properties

Mechanism of action Tiotropium: LAMA with similar affinity for muscarinic receptors $\mathrm{M}_{1}$ to $\mathrm{M}_{5}$; displays kinetic subtype selectivity; binds competitively and reversibly to $\mathrm{M}_{3}$ receptors on airway smooth muscle cells; inhibits action of acetylcholine at muscarinic receptors, leading to smooth muscle relaxation

Olodaterol: potent and highly selective LABA; binds to and activates $\beta_{2}$ receptors on airway smooth muscle cells; stimulates intracellular adenyl cyclase and $\uparrow$ synthesis of cyclic-3',5' adenosine monophosphate, resulting in smooth muscle relaxation and bronchodilation

In vitro $\quad \uparrow$ attenuation of tumour growth factor $\beta$-mediated neutrophilic inflammation with combination vs. individual agents

In animals $\quad \uparrow$ protection against lipopolysaccharide-induced airway hyper-responsiveness and acetylcholine-induced bronchoconstriction with combination vs. individual agents

In pts with COPD Tiotropium: dose-dependent bronchodilation; duration of action $\geq 24 \mathrm{~h}$; peak response seen at $1.5-2 \mathrm{~h}$ post-dose; improved lung function and $\downarrow$ exacerbations; therapeutic $(18 \mu \mathrm{g})$ and supratherapeutic $(54 \mu \mathrm{g})$ doses did not significantly prolong QT interval

Olodaterol: fast onset of action; duration of action $\geq 24 \mathrm{~h}$; improved lung function; dose-related prolongation of $1.6-6.5 \mathrm{~ms}$ in QT interval with single doses of $10-50 \mu \mathrm{g}$

Pharmacokinetic properties

Pharmacokinetics of inhaled tiotropium and olodaterol in FDC similar to those of each agent administered separately

Tiotropium: $\approx 33 \%$ of dose reaches systemic circulation; $\mathrm{C}_{\max }$ reached after 5-7 $\mathrm{min}$; steady-state reached by day 7 with no accumulation thereafter; $72 \%$ bound to plasma proteins; $\mathrm{Vd} 32 \mathrm{~L} / \mathrm{kg}$; non-enzymatically cleaved to the alcohol $\mathrm{N}$-methylscopine and dithienylglycolic acid; $19 \%$ of dose excreted in urine; terminal elimination half-life $\approx 25 \mathrm{~h}$

Olodaterol: $\mathrm{C}_{\max }$ reached within $10-20 \mathrm{~min}$; steady-state reached after 8 days; absolute bioavailability $\approx 30 \%$; plasma protein binding $\approx 60 \%$; Vd $1110 \mathrm{~L}$; metabolized by direct glucuronidation and O-demethylation with subsequent conjugation; substrate of P-gp, OAT1, OAT3 and OCT1 transporters; total CL $872 \mathrm{~mL} / \mathrm{min}$; renal CL $173 \mathrm{~mL} / \mathrm{min}$; $5-7 \%$ of dose excreted unchanged in urine; terminal elimination half-life $\approx 45 \mathrm{~h}$

Special populations $^{\mathrm{a}} \quad$ No dosage adjustments of FDC required in elderly or renally or hepatically impaired pts

Trend for $\uparrow$ systemic exposure to olodaterol in Japanese and other Asian pts vs. Caucasian pts

Drug interactions $^{\mathrm{a}} \quad$ Coadministration of FDC with other anticholinergic agents is not recommended or should be avoided; coadministration of FDC with other adrenergic agents may $\uparrow$ adverse events

Xanthine derivatives, steroids or non-potassium sparing diuretics coadministered with FDC may $\uparrow$ hypokalaemic effects and ECG changes associated with olodaterol; monoamine oxidase inhibitors, tricyclic antidepressants and other QTc-prolonging drugs may $\uparrow$ cardiovascular effects of, and $\beta$-adrenergic receptor antagonists may $\downarrow$ or antagonize the effects of, olodaterol in the FDC

Pharmacokinetics of each active substance not altered to clinically relevant extent when administered as FDC; no pharmacokinetic drug interaction studies have been performed with FDC

Exposure to tiotropium not altered to clinically relevant extent when coadministered with LABAs and ICS

No relevant pharmacokinetic interactions between olodaterol and fluconazole (CYP2C9 inhibitor) or ketoconazole (P-gp and CYP3A4 inhibitor); therapeutic doses of olodaterol did not inhibit CYP enzymes or drug transporters

$\uparrow$ increase/s, $\downarrow$ decrease/d, $C_{\max }$ maximum plasma concentration, $C L$ clearance, $C O P D$ chronic obstructive pulmonary disease, $F D C$ fixed-dose combination, ICS inhaled corticosteroids, $L A B A(s)$ long-acting $\beta_{2}$-adrenergic agonist(s), LAMA long-acting muscarinic antagonist, pts patients, $V d$ volume of distribution

${ }^{\mathrm{a} C}$ Consult local prescribing information for detailed recommendations 
pivotal TOnado 1 and 2 trials [9] and the OTEMTO 1 and 2 [10], VIVACITO [11] and ENERGITO [12] trials. Other outcomes, including dyspnoea, inspiratory capacity, exercise endurance and COPD exacerbations, were assessed in the randomized, double-blind [13-15] or partially double-blind [16], multinational, phase III MORACTO 1 and 2 [14], TORRACTO [15], PHYSACTO [16] and DYNAGITO [13] trials, as well as the multinational phase IV OTIVATO trial [17].

Inclusion criteria were age $\geq 40$ years [9-13] or 40-75 years [14-17]; a diagnosis of moderate to severe [Global initiative for chronic Obstructive Lung Disease (GOLD) stage 2-3] [10, 12, 14-17] or moderate to very severe (GOLD stage 2-4) [9, 11] COPD; a post-bronchodilator forced expiratory volume in $1 \mathrm{~s}\left(\mathrm{FEV}_{1}\right)$ of $<60 \%$ predicted $[13],<80 \%$ predicted $[9,11]$ or $\geq 30$ to $<80 \%$ predicted $[10$, $12,14-17]$; a post-bronchodilator $\mathrm{FEV}_{1}$ /forced vital capacity (FVC) of $<70 \%$ [9-16]; and a smoking history of $\geq 10$ packyears [9-17]. Baseline characteristics were generally similar across treatment groups in individual studies [9-17]. In all trials, tiotropium/olodaterol, the individual components and placebo were administered once daily via the Respimat ${ }^{\circledR}$ inhaler [9-17]. In ENERGITO, fluticasone propionate/salmeterol was administered twice daily via the Accuhaler ${ }^{\circledR}$ [12]. Where stated, patients could continue receiving ICS [9-11, 13-17], and salbutamol was provided as rescue medication [9-16].

\subsubsection{Lung Function}

Tiotropium/olodaterol $5 / 5 \mu \mathrm{g} /$ day improved lung function to a greater extent than the individual components (tiotropium $5 \mu \mathrm{g} /$ day or olodaterol $5 \mu \mathrm{g} /$ day) or placebo in patients with moderate to very severe COPD in the TOnado and OTEMTO trials $[9,10]$.

In the 52-week TOnado 1 and 2 trials, $\mathrm{FEV}_{1}$ area under the curve (AUC) from $0-3 \mathrm{~h}\left(\mathrm{AUC}_{0-3}\right)$ and trough $\mathrm{FEV}_{1}$ responses (i.e. adjusted mean changes from baseline) at week 24 (co-primary endpoints) were significantly greater in the tiotropium/olodaterol group than the tiotropium or olodaterol monotherapy groups in patients with moderate to very severe COPD (Table 2) [9]. The improvements in lung function were sustained over 52 weeks; significant $(p<0.05)$ improvements in $\mathrm{FEV}_{1} \mathrm{AUC}_{0-3}$ and trough $\mathrm{FEV}_{1}$ responses were seen with tiotropium/olodaterol relative to the individual components on all test days [9].

A prespecified combined analysis of TOnado 1 and 2 supported the findings of the individual studies (Table 2) [9]. Moreover, in subgroup analyses, some of which were post hoc [18-21], improvements in lung function (assessed by $\mathrm{FEV}_{1}$ $\mathrm{AUC}_{0-3}$ and trough $\mathrm{FEV}_{1}$ responses) with tiotropium/olodaterol versus tiotropium and olodaterol at week 24 were observed regardless of sex [9], baseline ICS use [9], age [18], prior LABA or LAMA maintenance treatment [19], baseline $\beta$-blocker use [20] or presence of chronic bronchitis and/or emphysema [21]. Tiotropium/olodaterol significantly $(p<0.005)$ improved lung function relative to tiotropium and olodaterol both in patients with GOLD stage 2 and in those with GOLD stage 3-4 disease at baseline [19]. However, these improvements with tiotropium/ olodaterol were generally numerically greater in patients with less severe COPD (i.e. GOLD stage 2) than in those with more severe COPD (i.e. GOLD stage 3-4) [19].

In the combined analysis of TOnado 1 and 2, secondary lung function endpoints (FVC $\mathrm{AUC}_{0-3}$ and trough $\mathrm{FVC}$ ) at week 24 were also significantly $(p<0.0001)$ improved with tiotropium/olodaterol versus the individual components [9].

In the 12-week OTEMTO trials, tiotropium/olodaterol significantly improved lung function (assessed by $\mathrm{FEV}_{1}$ $\mathrm{AUC}_{0-3}$ and trough $\mathrm{FEV}_{1}$; co-primary endpoints) relative to tiotropium or placebo in patients with moderate to severe COPD (Table 2) [10]. In post hoc analyses, improvements in lung function with tiotropium/olodaterol versus tiotropium and placebo at week 12 were observed regardless of age [18], disease severity (i.e. GOLD stage 2 and 3 and GOLD A-D subgroups) [22], use of previous maintenance therapy [22] or baseline dyspnoea burden [23].

2.1.1.1 Over 24-h Interval Tiotropium/olodaterol was associated with greater improvements in lung function over the 24-h dosing interval than the individual components or placebo in patients with moderate to very severe COPD in the 6-week VIVACITO trial [11]. After 6 weeks of treatment, $\mathrm{FEV}_{1}$ AUC from 0-24 h ( $\mathrm{AUC}_{0-24}$; primary endpoint), $\mathrm{FEV}_{1}$ AUC from 0-12 $\mathrm{h}\left(\mathrm{AUC}_{0-12}\right)$ and $\mathrm{FEV}_{1}$ AUC from $12-24 \mathrm{~h}\left(\mathrm{AUC}_{12-24}\right)$ responses (i.e. adjusted mean changes from baseline) were significantly greater with tiotropium/ olodaterol than with tiotropium, olodaterol and placebo (Table 3) [11].

Other $\mathrm{FEV}_{1}$ endpoints, including peak $\mathrm{p}_{0-3} \mathrm{FEV}_{1}$ (i.e. maximum $\mathrm{FEV}_{1}$ value obtained in the first $3 \mathrm{~h}$ after dosing) and trough $\mathrm{FEV}_{1}$ responses at week 6 , were also significantly $(p<0.0001)$ improved with tiotropium/olodaterol relative to the individual components or placebo [11]. Of note, the improvement in trough $\mathrm{FEV}_{1}$ with tiotropium/olodaterol versus placebo $(0.207 \mathrm{~L})$ was greater than the minimal clinically important difference (MCID). Significant $(p<0.0001)$ improvements in peak ${ }_{0-3} \mathrm{FEV}_{1}$ and trough $\mathrm{FEV}_{1}$ responses were also seen with tiotropium and olodaterol monotherapies relative to placebo [11].

FVC 24-h time profiles also demonstrated numerical improvement with tiotropium/olodaterol versus the monotherapies or placebo at week 6 [11]. Functional residual capacity and residual volume responses at 2.5 and $22.5 \mathrm{~h}$ post-dose (measured using body plethysmography in a subset of 143 patients) were improved to a significantly 
Table 2 Efficacy of tiotropium/olodaterol in patients with moderate to very severe [9] or moderate to severe [10] COPD

\begin{tabular}{|c|c|c|c|c|c|c|c|c|}
\hline \multirow[t]{2}{*}{ Study (timepoint) } & \multirow[t]{2}{*}{$\begin{array}{l}\text { Treatment } \\
(\mu \mathrm{g} / \text { day })\end{array}$} & \multirow[t]{2}{*}{ No. of $\mathrm{pts}^{\mathrm{a}}$} & \multicolumn{2}{|c|}{$\begin{array}{l}\mathrm{FEV}_{1} \mathrm{AUC}_{0-3} \text { response } \\
(\mathrm{L})^{\mathrm{b}, \mathrm{c}}\end{array}$} & \multicolumn{2}{|c|}{$\begin{array}{l}\text { Trough } \mathrm{FEV}_{1} \text { response } \\
(\mathrm{L})^{\mathrm{b}, \mathrm{c}}\end{array}$} & \multicolumn{2}{|c|}{ SGRQ total score ${ }^{b, d}$} \\
\hline & & & & $\begin{array}{l}\text { Diff from TIO/ } \\
\text { OLO }\end{array}$ & & $\begin{array}{l}\text { Diff from TIO/ } \\
\text { OLO }\end{array}$ & Mean values & Diff from TIO/OLO \\
\hline \multirow{3}{*}{$\begin{array}{c}\text { TOnado } 1 \text { [9] } \\
\text { (24 weeks) }\end{array}$} & TIO/OLO 5/5 & 522 & 0.256 & & 0.136 & & & \\
\hline & TIO 5 & 526 & 0.139 & $0.117 * * *$ & 0.065 & $0.071 * * *$ & & \\
\hline & OLO 5 & 525 & 0.133 & $0.123 * * *$ & 0.054 & $0.082 * * *$ & & \\
\hline \multirow{3}{*}{$\begin{array}{l}\text { TOnado } 2 \text { [9] } \\
\text { (24 weeks) }\end{array}$} & TIO/OLO 5/5 & 502 & 0.268 & & 0.145 & & & \\
\hline & TIO 5 & 500 & 0.165 & $0.103 * * *$ & 0.096 & $0.050 * * *$ & & \\
\hline & OLO 5 & 507 & 0.136 & $0.132 * * *$ & 0.057 & $0.088 * * *$ & & \\
\hline \multirow{3}{*}{$\begin{array}{l}\text { TOnado combined } \\
\text { analysis [9] } \\
\text { (24 weeks) }\end{array}$} & TIO/OLO 5/5 & 1023 & & & & & 36.67 & \\
\hline & TIO 5 & 1026 & & $0.110 * * *$ & & $0.060 * * *$ & 37.91 & $-1.23 *$ \\
\hline & OLO 5 & 1032 & & $0.128 * * *$ & & $0.085 * * *$ & 38.37 & $-1.69 * *$ \\
\hline \multirow{3}{*}{$\begin{array}{l}\text { OTEMTO } 1 \text { [10] } \\
\text { (12 weeks) }\end{array}$} & TIO/OLO 5/5 & 202 & & & & & 37.14 & \\
\hline & TIO 5 & 203 & & $0.111 * * *, \mathrm{e}$ & & $0.028 *, \mathrm{e}$ & 39.64 & $-2.49^{*, \mathrm{e}}$ \\
\hline & PL & 204 & & $0.331 * * *$ & & $0.162 * * *$ & 42.04 & $-4.89 * * *$ \\
\hline \multirow{3}{*}{$\begin{array}{l}\text { OTEMTO } 2 \text { [10] } \\
\text { (12 weeks) }\end{array}$} & TIO/OLO 5/5 & 200 & & & & & 38.01 & \\
\hline & TIO 5 & 201 & & $0.105^{* * *, \mathrm{e}}$ & & $0.039 *, \mathrm{e}$ & 39.73 & $-1.72^{\mathrm{e}}$ \\
\hline & PL & 199 & & $0.299 * * *$ & & $0.166^{* * * *}$ & 42.58 & $-4.56 * * *$ \\
\hline
\end{tabular}

SGRQ total score at BL was 43.51 in the TOnado combined analysis, 42.43 in OTEMTO 1 and 42.70 in OTEMTO 2

$A U C_{0-3}$ area under the curve from 0-3 h, $B L$ baseline, $C O P D$ chronic obstructive pulmonary disease, diff difference, $F E V_{l}$ forced expiratory volume in $1 \mathrm{~s}, O L O$ olodaterol, $P L$ placebo, pts patients, $S G R Q$ St George's Respiratory Questionnaire, $T I O$ tiotropium

$* p<0.05, * * p<0.005, * * * p \leq 0.0001$ vs. TIO/OLO $5 / 5$

${ }^{\mathrm{a}}$ No. of pts evaluable for $\mathrm{FEV}_{1} \mathrm{AUC}_{0-3}$ response

${ }^{\mathrm{b}}$ Co-primary endpoints

${ }^{\mathrm{c}}$ Response defined as adjusted mean change from BL

${ }^{\mathrm{d}}$ A reduction in score indicates improvement

${ }^{\mathrm{e}}$ In OTEMTO 1 and 2, TIO 5 pts also had significantly greater improvements in $\mathrm{FEV}_{1} \mathrm{AUC}_{0-3}$ response (between-group diff 0.219 and $0.194 \mathrm{~L}$; $p<0.0001)$, trough $\mathrm{FEV}_{1}$ response $(0.134$ and $0.127 \mathrm{~L} ; p<0.0001)$ and SGRQ total scores $(-2.40$ and $-2.85 ; p<0.05)$ than PL pts

$(p<0.05)$ greater extent with tiotropium/olodaterol than with tiotropium, olodaterol or placebo. All treatments significantly $(p<0.05)$ increased inspiratory capacity relative to placebo at 2.5 and $22.5 \mathrm{~h}$ post-dose, as well as total lung capacity at $2.5 \mathrm{~h}$ post-dose. Tiotropium/olodaterol significantly $(p<0.05)$ increased inspiratory capacity relative to tiotropium and olodaterol at $2.5 \mathrm{~h}$ post-dose [11].

Once-daily tiotropium/olodaterol was superior to twicedaily fluticasone propionate/salmeterol at improving lung function in patients with moderate to severe COPD in the 6-week ENERGITO trial [12]. Tiotropium/olodaterol 5/5 $\mu \mathrm{g}$ once daily improved $\mathrm{FEV}_{1} \mathrm{AUC}_{0-12}$ response (primary endpoint) to a significantly greater extent than fluticasone propionate/salmeterol $250 / 50$ or $500 / 50 \mu \mathrm{g}$ twice daily (Table 3 ). Significant $(p<0.0001)$ improvements with tiotropium/olodaterol over fluticasone propionate/salmeterol were also seen for $\mathrm{FEV}_{1} \mathrm{AUC}_{0-24}, \mathrm{FEV}_{1} \mathrm{AUC}_{12-24}$ (Table 3), peak ${ }_{0-3} \mathrm{FEV}_{1}$ and trough $\mathrm{FEV}_{1}$ responses. Changes in FVC AUC, peak $0-3$ FVC and trough FVC after 6 weeks of treatment were significantly $(p<0.0001)$ greater with tiotropium/olodaterol than with fluticasone propionate/salmeterol, with these improvements maintained over the full 24-h dosing interval [12]. A post hoc analysis showed that tiotropium/olodaterol improved lung function relative to fluticasone propionate/salmeterol, regardless of prior ICS, LAMA or LABA use [24].

\subsubsection{Health-Related Quality of Life}

Tiotropium/olodaterol $5 / 5 \mu \mathrm{g} /$ day was associated with clinically meaningful improvements in HR-QoL in patients with moderate to very severe COPD in the TOnado and OTEMTO trials $[9,10]$.

In the combined analysis of TOnado 1 and 2, tiotropium/olodaterol significantly improved St George's Respiratory Questionnaire (SGRQ) total scores at week 24 (co-primary endpoint) compared with the individual components (Table 2) [9]; improvements were seen in all SGRQ domains [5]. The improvement from baseline in SGRQ total score exceeded the MCID of $\geq 4$ units in all treatment groups $(-6.8,-5.6$ and -5.1 with tiotropium/olodaterol, 
Table 3 Lung function with tiotropium/olodaterol in patients with moderate to very severe [11] or moderate to severe [12] COPD

\begin{tabular}{|c|c|c|c|c|c|}
\hline \multirow[t]{2}{*}{ Study } & \multirow[t]{2}{*}{ Treatment ( $\mu \mathrm{g} /$ day $)$} & \multirow[t]{2}{*}{ No. of pts } & \multicolumn{3}{|c|}{ Response $^{\mathrm{a}}$ after 6 weeks of treatment $(\mathrm{L})$} \\
\hline & & & $\mathrm{FEV}_{1} \mathrm{AUC}_{0-24}{ }^{\mathrm{b}}$ & $\mathrm{FEV}_{1} \mathrm{AUC}_{0-12}{ }^{\mathrm{c}}$ & $\mathrm{FEV}_{1} \mathrm{AUC}_{12-24}$ \\
\hline \multirow[t]{4}{*}{ VIVACITO [11] } & TIO/OLO 5/5 & 138 & $0.244^{* *}$ & $0.305^{* *}$ & $0.182 * *$ \\
\hline & TIO 5 & 135 & 0.133 & 0.186 & 0.081 \\
\hline & OLO 5 & 136 & 0.129 & 0.179 & 0.079 \\
\hline & $\mathrm{PL}$ & 132 & -0.037 & -0.013 & -0.060 \\
\hline \multirow[t]{3}{*}{ ENERGITO [12] } & TIO/OLO 5/5 & 216 & $0.244 * *$ & $0.317 * *$ & $0.172 *$ \\
\hline & FP/SAL 50/500 & 217 & 0.159 & 0.188 & 0.129 \\
\hline & FP/SAL 50/250 & 211 & 0.162 & 0.192 & 0.132 \\
\hline
\end{tabular}

$A U C_{x-y}$ area under the curve from x-y h, $C O P D$ chronic obstructive pulmonary disease, $F E V_{l}$ forced expiratory volume in $1 \mathrm{~s}, F P$ fluticasone propionate, $O L O$ olodaterol, $P L$ placebo, pts patients, $S A L$ salmeterol, $T I O$ tiotropium

${ }^{*} p<0.001, * * p<0.0001$ vs. all comparators

${ }^{a}$ Response defined as adjusted mean change from baseline

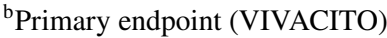

${ }^{c}$ Primary endpoint (ENERGITO)

tiotropium and olodaterol, respectively) [9]. However, the difference between tiotropium/olodaterol and tiotropium or olodaterol did not meet the threshold of clinical relevance (Table 2). At week 24, the SGRQ response rate (i.e. decrease of $\geq 4$ units from baseline in SGRQ total score, based on the MCID) was higher (nominal $p \leq 0.0001$ ) with tiotropium/ olodaterol than with tiotropium or olodaterol (58 vs. 49 and $45 \%$, respectively). The responder analysis odds ratio (OR) was 1.426 for tiotropium/olodaterol versus tiotropium and 1.670 for tiotropium/olodaterol versus olodaterol [9]. Significantly $(p<0.01)$ fewer tiotropium/olodaterol recipients were classed as SGRQ deteriorators (i.e. increase of $\geq 4$ units from baseline in SGRQ total score) at week 24 compared with tiotropium and olodaterol recipients (14 vs. 19 and 19\%) [25]. At week 52, the time to SGRQ deterioration was significantly delayed with tiotropium/olodaterol versus tiotropium [hazard ratio (HR) 0.82 ; 95\% CI 0.70-0.96; $p<0.05]$ and olodaterol (HR 0.70; 95\% CI $0.60-0.82 ; p<0.0001$ ) [25].

In the shorter (12-week) OTEMTO trials, tiotropium/ olodaterol was associated with statistically and clinically significant improvements in SGRQ total scores relative to placebo (Table 2) [10]. SGRQ response rates at week 12 were significantly $(p<0.05)$ higher with tiotropium/olodaterol than with tiotropium and placebo in OTEMTO 1 (53 vs. 42 and 31\%, respectively) and in OTEMTO 2 (52 vs. 41 and $33 \%$, respectively) [10]. Significantly $(p<0.05)$ fewer patients were classed as SGRQ deteriorators with tiotropium/olodaterol versus tiotropium and placebo (18 vs. 23 and $30 \%$, respectively) [25].

\subsubsection{Dyspnoea}

Tiotropium/olodaterol $5 / 5 \mu \mathrm{g} /$ day improved dyspnoea to a greater extent than the individual components or placebo in patients with moderate to very severe COPD in the TOnado and OTEMTO trials $[9,10]$.

In the combined analysis of TOnado 1 and 2, the Mahler Transition Dyspnoea Index (TDI) focal score at week 24 was significantly $(p<0.05)$ improved with tiotropium/olodaterol relative to tiotropium (mean treatment difference 0.36 ) and olodaterol (mean treatment difference 0.42) [9]. The proportion of patients with a TDI response (i.e. clinically relevant increase of $\geq 1$ unit from baseline in TDI focal score) was significantly $(p<0.01)$ higher with tiotropium/ olodaterol (55\%) than olodaterol (48\%), but not tiotropium (51\%) [25]. The proportion of patients classed as TDI deteriorators (i.e. increase of $\geq 1$ unit from baseline in TDI focal score) at week 24 was not significantly different between the tiotropium/olodaterol, tiotropium and olodaterol groups (10, 13 and $11 \%$, respectively; values estimated from a graph). At week 52, the time to TDI deterioration was significantly $(p<0.05)$ delayed with tiotropium/olodaterol versus tiotropium (HR 0.84; 95\% CI 0.72-0.98) and olodaterol (HR 0.82; 95\% CI 0.71-0.96) [25].

At week 12 in the OTEMTO trials, tiotropium/olodaterol significantly improved the TDI focal score compared with tiotropium (mean treatment difference of 0.61 in OTEMTO 1 and 0.58 in OTEMTO 2; both $p<0.05$ ) and placebo (mean treatment difference of 2.05 in OTEMTO 1 and 1.20 in OTEMTO 2; both $p<0.0001$ ) [10]. The differences between tiotropium/olodaterol and placebo met the $\geq 1$ unit threshold for clinical relevance [10]. Significantly $(p<0.001)$ more tiotropium/olodaterol (54\%) than tiotropium (41\%) and placebo $(26 \%)$ recipients were classed as TDI responders, and significantly $(p<0.0001)$ fewer tiotropium/olodaterol $(9 \%)$ and tiotropium $(11 \%)$ versus placebo $(23 \%)$ recipients were classed as TDI deteriorators [25]. 


\subsubsection{Inspiratory Capacity and Exercise Endurance}

Tiotropium/olodaterol $5 / 5 \mu \mathrm{g} /$ day improved inspiratory capacity and exercise endurance in patients with COPD in the MORACTO, TORRACTO, PHYSACTO and OTIVATO trials [14-17].

In the 6-week MORACTO 1 and 2 trials $(n=586)$, tiotropium/olodaterol significantly $(p<0.0001)$ improved mean inspiratory capacity pre-exercise (co-primary endpoint) relative to tiotropium, olodaterol and placebo (treatment differences of 0.101, 0.099 and $0.254 \mathrm{~L}$, respectively) [14]. These improvements were sustained during exercise at both isotime and end-exercise. Tiotropium/olodaterol also significantly increased mean exercise endurance time (EET) during constant work-rate cycle ergometry (CWRCE; co-primary endpoint) relative to placebo $(17.3 \% ; p<0.0001)$ and olodaterol $(5.6 \% ; p<0.05)[14]$.

In the TORRACTO trial $(n=404)$, endurance time during CWRCE after 12 weeks of treatment (primary endpoint) increased by $13.8 \%$ with tiotropium/olodaterol versus placebo $(p=0.02)$ [15]. In the endurance shuttle walk test substudy $(n=165)$, EET increased by $20.9 \%$ with tiotropium/ olodaterol versus placebo. This improvement was beyond the proposed MCID for this parameter; however, the difference between tiotropium/olodaterol and placebo was not statistically significant. Mean inspiratory capacity at pre-exercise, isotime and end-exercise increased with tiotropium/olodaterol compared with placebo at weeks 6 and 12 (nominal $p<0.05)$ [15].

Tiotropium/olodaterol, with or without exercise training, improved exercise endurance in patients participating in a self-management behaviour-modification programme in the 12-week PHYSACTO trial $(n=304)$ [16]. Compared with placebo, significant increases in EET at week 8 (primary endpoint) were observed with tiotropium/olodaterol (29.2\%; $p=0.0109)$ and tiotropium/olodaterol plus exercise training $(45.8 \% ; p=0.0002)$. Distance walked during the 6 -min walking test was significantly $(p<0.05)$ greater with tiotropium/olodaterol versus placebo (difference of $27 \mathrm{~m}$ with exercise training and $21 \mathrm{~m}$ without exercise training). Tiotropium/olodaterol, with or without exercise training, was not associated with increased physical activity compared with placebo (as measured by the number of steps per day, average walking time per day and average walking intensity) [16].

Tiotropium/olodaterol was more effective than tiotropium at reducing activity-related breathlessness in patients with lung hyperinflation at rest in the 6-week OTIVATO trial $(n=106)$ [17]. The mean change from baseline in intensity of breathlessness measured using the modified Borg scale at the end of the 3-min constant speed shuttle test (primary endpoint) was significantly ( $p=0.0217)$ greater with tiotropium/olodaterol than with tiotropium ( -0.968 vs. -1.325$)$.
Tiotropium/olodaterol was also significantly $(p<0.0001)$ more effective than tiotropium at improving inspiratory capacity (treatment difference $0.218 \mathrm{~L}$ ). The proportion of patients with a $\geq 1$-point improvement in the modified Borg dyspnoea score was $50 \%$ with tiotropium/olodaterol and $34 \%$ with tiotropium, resulting in a number needed to treat of 7 to achieve a clinically relevant improvement in activity-related breathlessness for tiotropium/olodaterol versus tiotropium [17].

\subsubsection{Rescue Medication and Exacerbations}

Tiotropium/olodaterol reduced the need for rescue medication relative to the individual components or placebo in patients with moderate to very severe COPD in the TOnado and OTEMTO trials $[5,25]$. At week 12 in the OTEMTO trials, night-time rescue medication use was reduced by $0.42 \mathrm{puffs} / \mathrm{night}$ with tiotropium/olodaterol versus tiotropium $(p<0.001)$ and by $1.00 \mathrm{puff} / \mathrm{night}$ versus placebo $(p<0.0001)$ [25]. In the combined analysis of TOnado 1 and 2, tiotropium/olodaterol recipients used significantly $(p<0.0001)$ less daytime (mean 0.76 vs. 0.97 and 0.87 occasions/day) and night-time (mean 1.24 vs. 1.69 and 1.52 occasions/day) rescue salbutamol than tiotropium and olodaterol recipients [5]. At week 52 in the TOnado trials, the use of night-time rescue medication was reduced by $0.55 \mathrm{puffs} / \mathrm{night}$ with tiotropium/olodaterol versus tiotropium $(p<0.0001)$ and by 0.28 puffs/night versus olodaterol $(p<0.01)[25]$.

In the 52-week DYNAGITO trial $(n=7903)$, there was no significant reduction in the rate of COPD exacerbations with tiotropium/olodaterol compared with tiotropium alone in patients with a history of exacerbations [13]. The rate ratio (RR) for the rate of moderate and severe exacerbations from the first dose of medication until 1 day after the last drug administration (primary endpoint) was 0.93 (99\% CI 0.85-1.02) with tiotropium/olodaterol compared with tiotropium $(p=0.0498)$, which did not meet the targeted significance level of $p<0.01$. However, tiotropium/olodaterol reduced the rate of exacerbations treated with ICS alone compared with tiotropium (RR $0.80 ; 95 \%$ CI $0.68-0.94 ; p=0.0068$ ). Adjusting for multiple baseline covariates led to a reduction in the annualized rate of exacerbations with tiotropium/olodaterol versus tiotropium of 9-11\% (nominal $p<0.01$ ) [13].

The combined analysis of TOnado 1 and 2 also demonstrated no significant difference between tiotropium/ olodaterol and tiotropium in the risk of moderate/severe COPD exacerbation (risk ratio $0.92 ; 95 \%$ CI $0.78-1.09$ ) [9]. The risk of moderate/severe exacerbation was significantly ( $p=0.0332)$ lower with tiotropium/olodaterol versus olodaterol (risk ratio 0.83 ; 95\% CI 0.71-0.99). However, it should be noted that the TOnado trials were not designed to assess the impact of tiotropium/olodaterol on COPD exacerbations [9]. 


\subsection{In Asian Patients}

Results in Asian patients were generally consistent with those seen in the overall clinical trial population. In a prespecified exploratory analysis of TOnado 1 and 2, FEV $\mathrm{AUC}_{0-3}$ and trough $\mathrm{FEV}_{1}$ responses at 24 weeks were significantly $(p<0.0001)$ greater with tiotropium/olodaterol than with tiotropium and olodaterol in the East Asian subpopulation $(n=709)$ [26]. Similarly, in the Japanese subpopulation of TOnado 1 and $2(n=413), \mathrm{FEV}_{1} \mathrm{AUC}_{0-3}$ and trough $\mathrm{FEV}_{1}$ responses at 24 weeks were greater (nominal $p<0.0001$ ) with tiotropium/olodaterol than with tiotropium and olodaterol [27]. In a prespecified subgroup analysis of Japanese patients in DYNAGITO $(n=461)$, tiotropium/ olodaterol was associated with a $29 \%$ lower risk of COPD exacerbation than tiotropium (RR $0.71 ; 99 \%$ CI $0.46-1.10$; $p=0.0434)$ [28].

The randomized, double-blind, multicentre, phase III VESUTO trial investigated the efficacy of tiotropium/olodaterol in Japanese patients with COPD $(n=184)$ [29]. Eligible patients were aged $\geq 40$ years and had been diagnosed with GOLD stage 2-4 COPD. They were required to have a post-bronchodilator $\mathrm{FEV}_{1}$ of $<80 \%$ predicted, a post-bronchodilator $\mathrm{FEV}_{1} / \mathrm{FVC}$ of $<70 \%$, a smoking history of $>10$ pack-years, a score of $\geq 1$ on the modified Medical Research Council (mMRC) dyspnoea scale, a 6-min walk distance (6MWD) test $<400 \mathrm{~m}$ and a score of $\geq 4$ on the modified Borg scale of breath discomfort at the end of the 6MWD test. Each morning patients self-administered tiotropium/olodaterol $5 / 5 \mu \mathrm{g}$ or tiotropium $5 \mu \mathrm{g}$ via the Respimat ${ }^{\circledR}$ inhaler. After 6 weeks, patients crossed over to the other treatment for a further 6 weeks [29].

Tiotropium/olodaterol improved lung function to a greater extent than tiotropium [29]. After 6 weeks of treatment, the adjusted mean inspiratory capacity at rest (measured at $60 \mathrm{~min}$ post-dose; primary endpoint) was significantly $(p<0.0001)$ higher with tiotropium/olodaterol than with tiotropium (1.990 vs. $1.875 \mathrm{~L}$ ). Tiotropium/olodaterol was also associated with significant $(p<0.0001)$ improvements in $\mathrm{FEV}_{1}$ (1.275 vs. $\left.1.169 \mathrm{~L}\right), \mathrm{FVC}$ (3.020 vs. $2.857 \mathrm{~L})$ and slow vital capacity (3.096 vs. $2.962 \mathrm{~L})$ relative to tiotropium. The adjusted mean 6MWD after 6 weeks of treatment was not significantly different between tiotropium/olodaterol and tiotropium (311.5 vs. $307.4 \mathrm{~m}$ ). However, in the subgroup of patients with GOLD stage 3-4 disease at baseline $(n=163)$, the adjusted mean 6MWD was significantly $(p=0.0254)$ increased with tiotropium/ olodaterol versus tiotropium (301.5 vs. 283.4 m; prespecified analysis). There were no significant between-group differences in physical activity, although tiotropium/olodaterol did significantly $(p<0.05)$ reduce sedentary time and increase active time compared with tiotropium in a post hoc analyses [29, 30].

\subsection{Comparison with Umeclidinium/Vilanterol}

A randomized, open-label, multinational, non-inferiority trial investigated the efficacy of tiotropium/olodaterol compared with umeclidinium/vilanterol in patients with COPD [31]. The trial enrolled patients aged $\geq 40$ years with a post-bronchodilator $\mathrm{FEV}_{1}$ of $\geq 50$ to $\leq 70 \%$ predicted, a pre-bronchodilator and post-bronchodilator $\mathrm{FEV}_{1} / \mathrm{FVC}$ of $<70 \%$, a smoking history of $\geq 10$ pack-years and a score of $\geq 2$ on the mMRC dyspnoea scale. They received tiotropium/olodaterol $5 / 5 \mu \mathrm{g}$ once daily via the Respimat ${ }^{\circledR}$ SMI or umeclidinium/vilanterol $62.5 / 25 \mu \mathrm{g}$ once daily via the Ellipta ${ }^{\circledR}$ dry powder inhaler (DPI) for 8 weeks. After a 3-week washout, patients crossed over to the other treatment for a further 8 weeks. Salbutamol was provided as rescue medication [31].

Umeclidinium/vilanterol was non-inferior to tiotropium/ olodaterol for the change from baseline in trough $\mathrm{FEV}_{1}$ at week 8 in the per-protocol population (primary endpoint; Table 4) [31]. Having established non-inferiority, the superiority of umeclidinium/vilanterol to tiotropium/olodaterol was shown for trough $\mathrm{FEV}_{1}$ at week 8 in the intent-to-treat population (Table 4$)$. In addition, significantly $(p<0.001)$ more umeclidinium/vilanterol than tiotropium/olodaterol recipients achieved a clinically meaningful increase $(\geq 0.100 \mathrm{~L})$ in trough $\mathrm{FEV}_{1}$ at both week 4 (69 vs. $51 \%$; OR 2.09 ; $95 \%$ CI $1.39-3.14$ ) and week 8 (66 vs. $48 \%$; OR 2.05; 95\% CI 1.34-3.14). Significant increases in FVC and inspiratory capacity and significant reductions in rescue medication use were observed with umeclidinium/vilanterol relative to tiotropium/olodaterol at weeks 4 and 8 (Table 4 ). There was a significant reduction in COPD Assessment Test (CAT) score with umeclidinium/vilanterol versus tiotropium/olodaterol at week 4, but not at week 8 (Table 4) [31].

\subsection{Real-World Experience}

Results from OTIVACTO, an open-label, observational study, support the beneficial effects of tiotropium plus olodaterol on self-reported physical functioning in patients with COPD in a real-world setting [32]. The study recruited 7443 patients in nine European countries who received tiotropium/olodaterol via the Respimat ${ }^{\circledR}$ inhaler for 6 weeks. At study end, $68 \%$ of patients achieved therapeutic success (i.e. 10-point increase in physical functioning score). Therapeutic success was seen in $64 \%$ of patients with infrequent $(\leq 1)$ exacerbations and $76 \%$ of patients with frequent $(\geq 2)$ exacerbations. With regard to general patient condition, the proportion of patients with an 8-point Physicians Global Evaluation (PGE) score of 3-4 (satisfactory) decreased from $56 \%$ at baseline to $16 \%$ at study end, while the proportion of patients with a PGE score of 5-7 (good/excellent) increased from $31 \%$ at baseline to $79 \%$ at study end. Most patients were satisfied/very satisfied with tiotropium/ 
Table 4 Efficacy of tiotropium/olodaterol versus umeclidinium/ vilanterol in patients with COPD [31]

LSM change from baseline

UMEC/VIL TIO/OLO

Per-protocol population $(n=227)$

Trough $\mathrm{FEV}_{1}$ (L)

\begin{tabular}{|c|c|c|}
\hline Week 4 & $0.181 * *$ & 0.141 \\
\hline Week $8^{\mathrm{a}}$ & $0.175^{* * *}$ & 0.122 \\
\hline \multicolumn{3}{|l|}{ [ntent-to-treat population $(n=236)$} \\
\hline \multicolumn{3}{|l|}{ Trough $\mathrm{FEV}_{1}(\mathrm{~L})$} \\
\hline Week 4 & $0.189 * * *$ & 0.141 \\
\hline Week 8 & $0.180 * * *$ & 0.128 \\
\hline \multicolumn{3}{|l|}{$\mathrm{FC}(\mathrm{L})$} \\
\hline Week 4 & $0.214^{*}$ & 0.174 \\
\hline Week 8 & $0.202 * * *$ & 0.135 \\
\hline \multicolumn{3}{|l|}{ nspiratory capacity (L) } \\
\hline Week 4 & $0.164 * *$ & 0.112 \\
\hline Week 8 & $0.169 * *$ & 0.122 \\
\hline Rescue medication use (no. puffs/day) ${ }^{b}$ & $-0.94 * * *$ & -0.68 \\
\hline No. of rescue medication-free days ${ }^{b}$ & 8.04 & 6.13 \\
\hline \multicolumn{3}{|l|}{ CAT score } \\
\hline Week 4 & $-1.60^{*}$ & -1.01 \\
\hline Week 8 & -1.38 & -1.26 \\
\hline
\end{tabular}

CAT COPD Assessment Test, COPD chronic obstructive pulmonary disease, $F E V_{1}$ forced expiratory volume in $1 \mathrm{~s}, F V C$ forced vital capacity, $L S M$ least squares mean, $O L O$ olodaterol, $T I O$ tiotropium, UMEC umeclidinium, VIL vilanterol

${ }^{*} p<0.05, * * p<0.01, * * * p<0.001$ vs. TIO/OLO

${ }^{a}$ Primary endpoint

${ }^{\mathrm{b}}$ During weeks $1-8$

olodaterol treatment $(81 \%)$, inhaling from the Respimat ${ }^{\circledR}$ device (84\%) and device handling (85\%) [32].

\section{Tolerability of Tiotropium/Olodaterol}

The tolerability profile of tiotropium/olodaterol $5 / 5 \mu \mathrm{g} /$ day was generally similar to that of the individual components (tiotropium $5 \mu \mathrm{g} /$ day and olodaterol $5 \mu \mathrm{g} /$ day) in patients with moderate to very severe COPD.

In a prespecified safety analysis of TOnado 1 and 2, adverse events (AEs) occurred in 74.0, 73.3 and $76.6 \%$ of tiotropium/olodaterol, tiotropium and olodaterol recipients, respectively [33]. The majority of AEs were of mild or moderate severity. Treatment-related AEs occurred in 7.1, 6.1 and $6.6 \%$ of patients in the tiotropium/olodaterol, tiotropium and olodaterol groups, serious AEs (SAEs) in 16.4, 16.7 and $17.4 \%$ of patients, fatal AEs in 1.7, 1.6 and $1.3 \%$ of patients, and $7.4,9.0$ and $9.9 \%$ of patients discontinued treatment because of AEs [33]. In TOnado 1 and 2, the most common treatment-emergent AEs (TEAEs) were respiratory events
[9]. TEAEs occurring in $>3 \%$ of tiotropium/olodaterol $5 / 5 \mu \mathrm{g} /$ day recipients and at a higher incidence with tiotropium/olodaterol than tiotropium or olodaterol were nasopharyngitis (12.4 vs. 11.7 and $12.6 \%)$, cough (3.9 vs. 4.4 and $3.0 \%$ ), dyspnoea (3.8 vs. 4.9 and $3.7 \%$ ), back pain (3.6 vs. 1.8 and $3.4 \%$ ), pneumonia (3.3 vs. 2.5 and $3.5 \%$ ) and bronchitis (3.0 vs. 2.2 and 3.2\%) [9].

In a pooled analysis of data from three 52-week trials (TOnado 1 and 2 and DYNAGITO), the rate of AEs per 100 patient-years (PY) was 152.66 with tiotropium/olodaterol and 158.33 with tiotropium (exposure-adjusted RR 0.96 ; $95 \%$ CI $0.92-1.01$ ) [34]. There were 22.16 and 24.22 SAEs per $100 \mathrm{PY}$ with tiotropium/olodaterol and tiotropium (RR $0.91 ; 95 \%$ CI $0.84-1.00$ ). The rate of AEs leading to discontinuation was 6.11 per $100 \mathrm{PY}$ with tiotropium/olodaterol and 8.44 per $100 \mathrm{PY}$ with tiotropium (RR $0.72 ; 95 \% \mathrm{CI}$ 0.62-0.84). The rate of respiratory, thoracic and mediastinal disorders per $100 \mathrm{PY}$ was 70.04 with tiotropium/olodaterol and 74.72 with tiotropium (RR 0.94; 95\% CI 0.89-0.99). The most common AEs were COPD exacerbation (55.42 and 57.46 events per $100 \mathrm{PY}$ ), viral upper respiratory tract infection (URTI; 8.97 and 9.28 events per $100 \mathrm{PY}$ ) and dyspnoea (5.23 and 6.40 events per $100 \mathrm{PY}$ ) [34].

Like other LABAs, olodaterol may potentially cause cardiovascular effects, including increased heart rate, increased BP and ECG changes [2, 3, 5]. In the prespecified safety analysis of TOnado 1 and 2, major adverse cardiac events (MACE) occurred in 2.3, 1.8 and 2.4\% of tiotropium/olodaterol, tiotropium and olodaterol recipients, respectively [33]. The exposure-adjusted RRs for tiotropium/olodaterol versus the individual components were 1.24 (95\% CI 0.68-2.26) for tiotropium and 0.94 (95\% CI 0.53-1.64) for olodaterol, indicating no statistically significant difference [33]. In the pooled analysis of TOnado 1 and 2 and DYNAGITO, the incidence of MACE per $100 \mathrm{PY}$ was 2.11 with tiotropium/olodaterol and 2.22 with tiotropium (RR 0.95; 95\% CI 0.72-1.25) [34]. Among the subgroup of patients with a history of cardiac disorders, ischaemic heart disease, myocardial infarction, cardiac arrhythmia, cardiac failure, cardiac arrest or cerebrovascular events $(n=2823)$, the incidence of MACE per 100 PY was 3.23 with tiotropium/olodaterol and 5.08 with tiotropium (RR 0.64; $95 \%$ CI 0.44-0.93) [34]. Tiotropium/olodaterol may need to be discontinued if cardiovascular effects occur $[2,4,5]$. Tiotropium/olodaterol should be used with caution in patients with cardiovascular disorders [2-5].

Tiotropium/olodaterol, like other inhaled medicines, may cause potentially life-threatening paradoxical bronchospasm [2-5]. If paradoxical bronchospasm occurs, tiotropium/olodaterol should be discontinued immediately and substituted with alternative therapy [2-5]. Serious anticholinergic AEs have been associated with the use of tiotropium/olodaterol, including constipation, glaucoma, intestinal obstruction and 
urinary retention $[4,5]$. During 52-week clinical trials, the most common anticholinergic $\mathrm{AE}$ with tiotropium/olodaterol was dry mouth, which occurred in approximately $1.7 \%$ of patients (vs. $2.7 \%$ of tiotropium and $1 \%$ of olodaterol recipients) and led to treatment discontinuation in one patient [5]. Tiotropium/olodaterol should be used with caution in patients with bladder-neck obstruction [4, 5], narrow-angle glaucoma or prostatic hyperplasia [2-5]. During 52-week clinical trials, the most common $\beta_{2}$-adrenergic AEs with tiotropium/olodaterol were palpitations, tachycardia and hypertension [5]. The occurrence of other $\beta_{2}$-adrenergic AEs related to LABA use should be taken into consideration when using tiotropium/olodaterol $[4,5]$.

In other phase III trials in the TOviTO clinical trial programme, the tolerability profile of tiotropium/olodaterol was generally similar to that seen in the TOnado trials [10-16]. In the head-to-head comparison of tiotropium/olodaterol versus umeclidinium/vilanterol, both treatments had similar tolerability profiles [31]. AEs occurred in $31 \%$ of tiotropium/olodaterol recipients and $25 \%$ of umeclidinium/vilanterol recipients. The most common ( $>3 \%$ incidence) AEs were COPD exacerbation (8 vs. $8 \%$ ) and viral URTI (6 vs. 5\%) [31].

\subsection{In Asian Patients}

Tiotropium/olodaterol was generally well tolerated in Asian patients with moderate to very severe COPD [26-29, 35]. No important safety concerns were identified in a 52-week, randomized, double-blind, multicentre trial investigating the long-term safety of tiotropium/olodaterol in Japanese patients aged $\geq 40$ years $(n=122)$ [35]. AEs were reported in $85.4 \%$ of tiotropium/olodaterol $5 / 5 \mu \mathrm{g} /$ day recipients and $80.5 \%$ of olodaterol $5 \mu \mathrm{g} /$ day recipients. Treatment-related AEs occurred in 7 and 5\% of patients in the tiotropium/ olodaterol and olodaterol groups, SAEs in 7 and $12 \%$ of patients, and 5 and $15 \%$ of patients discontinued treatment because of AEs. Most AEs were of mild or moderate severity. AEs occurring in $\geq 10 \%$ of tiotropium/olodaterol $5 / 5 \mu \mathrm{g} /$ day recipients and at a higher incidence with tiotropium/olodaterol than olodaterol were COPD (22 vs. $15 \%$ ), bronchitis (15 vs. 7\%) and constipation (10 vs. 7\%) [35].

\section{Dosage and Administration of Tiotropium/ Olodaterol}

In the USA, tiotropium/olodaterol is indicated for the long-term, once-daily maintenance treatment of patients with COPD, including chronic bronchitis and/or emphysema [2]. In the EU, tiotropium/olodaterol is indicated as a maintenance bronchodilator treatment to relieve symptoms in adult patients with COPD [5]. In Japan, tiotropium/olodaterol is indicated for the relief of symptoms of airflow obstruction in patients with COPD, including chronic bronchitis and emphysema, when a combination of a long-acting inhaled anticholinergic agent and a long-acting inhaled $\beta_{2^{-}}$ adrenergic agonist is required [3]. In China, tiotropium/olodaterol is indicated for the long-term maintenance treatment of patients with COPD, including chronic bronchitis and emphysema, to relieve symptoms [4].

Tiotropium/olodaterol is orally inhaled via the Respimat ${ }^{\circledR}$ SMI [2-5]. The recommended dosage is tiotropium/olodaterol $5 / 5 \mu \mathrm{g}$ administered once daily as two puffs at the same time each day; each actuation from the inhaler is equivalent to a delivered dose of tiotropium/olodaterol $2.5 / 2.5 \mu \mathrm{g}$. Tiotropium/olodaterol is not indicated to treat acute deterioration of COPD (i.e. as rescue therapy for the treatment of acute episodes of bronchospasm) or for the treatment of asthma [2-5]. Local prescribing information should be consulted for further details regarding administration, contraindications, potential drug interactions, warning and precautions, and use in special patient populations.

\section{Place of Tiotropium/Olodaterol in the Management of COPD}

The goals of pharmacotherapy in patients with stable COPD are to reduce symptoms and to reduce the risk of future events (i.e. disease progression, exacerbations and mortality) [1]. Current GOLD treatment guidelines recommend a patient-specific approach to treatment. Until recently, patients with COPD were classified into four groups (GOLD A-D) based on the severity of airflow limitation (i.e. spirometric stages 1-4) and the risk of exacerbation. Although spirometry is vital for the diagnosis of COPD, symptom burden and risk of exacerbation are considered preferable for guiding therapy. The ABCD assessment tool has been refined to separate airflow limitation from clinical parameters, with GOLD A-D categories now assigned based on patient symptoms (assessed using mMRC and/or CAT scores) and history of exacerbations, allowing for a more individualized treatment approach [1].

Short- or long-acting bronchodilators are recommended as first-line therapy for patients in group A (i.e. fewer symptoms, low risk of exacerbation) [1]. Initial therapy for patients in groups $\mathrm{B}$ and $\mathrm{C}$ should consist of a single longacting bronchodilator. For patients in group D (i.e. more symptoms, high risk of exacerbation), treatment options include dual combination therapy with a LAMA plus a LABA or an ICS plus a LABA [1]. To avoid the need for separate inhalers and often different dosing schedules [36], several fixed-dose combinations of a LAMA and LABA in a single inhaler have been developed [1]. One such combination is tiotropium/olodaterol, which induces smooth muscle relaxation via two different mechanisms: inhibition of 
acetylcholine at muscarinic receptors (tiotropium) and direct stimulation of $\beta_{2}$-adrenergic receptors (olodaterol) (Table 1).

In phase III or IV clinical trials in patients with COPD, once-daily tiotropium/olodaterol improved lung function and provided symptomatic benefits (Sect. 2.1). Tiotropium/ olodaterol improved lung function to a greater extent than the individual components or placebo, with the benefit over the individual components seen regardless of factors such as sex, age, baseline ICS or $\beta$-blocker therapy, prior treatment with a LABA or LAMA, or the presence of chronic bronchitis and/or emphysema (Sect. 2.1.1). Tiotropium/ olodaterol provided consistently greater improvements in lung function over the 24-h dosing interval than the individual components, placebo or twice-daily fluticasone propionate/salmeterol (Sect. 2.1.1.1). In addition, tiotropium/ olodaterol improved HR-QOL to a clinically relevant extent (Sect. 2.1.2), improved dyspnoea (Sect. 2.1.3), improved inspiratory capacity and exercise endurance (Sect. 2.1.4) and reduced the need for rescue medication (Sect. 2.1.5).

Tiotropium/olodaterol did not reduce the risk of COPD exacerbations relative to tiotropium alone in the DYNAGITO trial (Sect. 2.1.5), which used a 1\% significance level; this may have been due in part to higher than expected variance in the patient population [13]. When data from DYNAGITO were analysed using multiple covariates models similar to those used in previous COPD trials, the difference between tiotropium/olodaterol and tiotropium became significant at the $1 \%$ level [13].

Results in Asian patients (Sect. 2.2) and in the real-world setting (Sect. 2.4). were generally consistent with those seen in the overall clinical trial population. Additional real-world studies are currently underway. The ongoing phase IV AIRWISE study (NCT03265145) is comparing the effect of tiotropium/ olodaterol versus ICS plus LABA plus LAMA triple combination therapy on the time to first moderate or severe COPD exacerbation in a real-world community-based setting $(n=3200)$. In addition, a prospective, observational, multinational study (NCT03663569) is currently recruiting patients (estimated $n=4500$ ) and will investigate the effect of tiotropium/olodaterol on therapeutic success in routine clinical practice.

To date, few trials have directly compared tiotropium/olodaterol with other fixed-dose combinations for the treatment of COPD. In an 8-week, open-label trial, umeclidinium/vilanterol was superior to tiotropium/olodaterol for the primary endpoint of trough $\mathrm{FEV}_{1}$ (Sect. 2.3). Previous network meta-analyses and other indirect comparisons have also demonstrated some apparent differences in efficacy among LAMA/LABA fixeddose combinations in patients with COPD, highlighting a potential effectiveness gradient within the LAMA/LABA class [37-39]. However, given the limitations of indirect comparisons, these results should be interpreted with caution. Further head-to-head randomized controlled trials comparing tiotropium/olodaterol with other fixed-dose combinations, including other LAMA/LABA combinations, would be of interest.
The tolerability profile of tiotropium/olodaterol in clinical trials was generally similar to that of the individual components (Sect. 3). The most common AEs were respiratory in nature. Few tiotropium/olodaterol recipients experienced anticholinergic or $\beta_{2}$-adrenergic AEs. Tiotropium/olodaterol was not associated with any increased risk of cardiovascular AEs or MACE compared with tiotropium alone, including in patients with cardiovascular history (Sect. 3). In a network meta-analysis indirectly comparing approved LAMA/ LABA fixed-dose combinations, the risk of cardiovascular SAEs was lower than placebo for aclidinium/formoterol and tiotropium/olodaterol, similar to placebo for umeclidinium/ vilanterol, and higher than placebo for glycopyrronium/ formoterol and glycopyrronium/indacaterol [40]. However, these results are considered exploratory in nature and should be interpreted with caution [40]. The impact of tiotropium/ olodaterol and other fixed-dose combinations on safety and tolerability requires further investigation in large postmarketing surveillance and observational studies.

Tiotropium/olodaterol is delivered via the Respimat ${ }^{\circledR}$ SMI. Unlike pressurized metered-dose inhalers (PMDIs) and DPIs, the Respimat ${ }^{\circledR}$ inhaler requires some assembly prior to use: a cartridge containing the drug solution is inserted into the inhaler and the device is primed $[2,4,5]$. In a study assessing real-life inhaler handling in patients with COPD, critical errors compromising drug delivery (mainly due to poor handlung synchronisation or dose preparation) were made in $47 \%$ of handlings with Respimat ${ }^{\circledR}$, compared with 15, 21, 29 and $32 \%$ of handlings with Breezhaler ${ }^{\circledR}$, Diskus ${ }^{\circledR}$, Handihaler $^{\circledR}$ and Turbuhaler ${ }^{\circledR}$, respectively [41]. Nevertheless, the physical properties of the aerosol generated by the Respimat ${ }^{\circledR}$ inhaler (i.e. particle/droplet size, aerosol velocity and duration of actuation) result in higher drug deposition in the lungs compared with aerosols generated by PMDIs or DPIs [42]. In addition, several design features of the Respimat ${ }^{\circledR}$ inhaler offer other advantages over other devices. For example, a dose indicator shows how many doses remain and automatically locks after the specified number of doses have been released $[2,4,5]$, preventing inhaler 'tail-off' that can occur with PMDIs [42].

Ease of use and patient preference are important factors that can affect adherence to inhaled medication and treatment success [43]. In a study evaluating preference and satisfaction between devices in patients with COPD (INHALATOR), more patients were satisfied with and preferred to use the Breezhaler ${ }^{\circledR}$ DPI than the Respimat ${ }^{\circledR}$ inhaler [44]. However, other studies have suggested that patients with COPD find the Respimat ${ }^{\circledR}$ inhaler easy to use and may prefer this inhaler over other devices including PMDIs and DPIs [43, $45,46]$. A new reusable Respimat ${ }^{\circledR}$ inhaler has been developed to replace the original disposable inhaler [47]. The updated inhaler can be reused with six cartridges, providing improved usability, greater convenience and reduced environmental impact [47]. 
COPD is associated with substantial healthcare costs [48]. Pharmacoeconomic analyses from the perspective of the French [49], Italian [50], Dutch [51] and UK [48] healthcare systems suggest that tiotropium/olodaterol is a cost-effective bronchodilator therapy for the maintenance treatment of COPD. In the UK, tiotropium/olodaterol was more cost-effective than aclidinium/formoterol, while the incremental costeffectiveness ratios for tiotropium/olodaterol, umeclidinium/ vilanterol and glycopyrronium/indacaterol were identical [48].

In conclusion, tiotropium/olodaterol $5 / 5 \mu \mathrm{g} / \mathrm{day}$ is effective and generally well tolerated in adults with moderate to very severe COPD. Therefore, tiotropium/olodaterol is a useful option for the maintenance treatment of COPD, with the convenience of once-daily administration via a single inhaler.

\section{Data Selection Tiotropium/Olodaterol: 290 records identified}

Duplicates removed

Excluded during initial screening (e.g. press releases; news reports; not relevant drug/indication; preclinical study; reviews; case reports; not randomized trial)

Excluded during writing (e.g. reviews; duplicate data; small patient number; nonrandomized/phase I/II trials)

Cited efficacy/tolerability articles 31

Cited articles not efficacy/tolerability

Search Strategy: EMBASE, MEDLINE and PubMed from 2016 to present. Previous Adis Drug Evaluation published in 2016 was hand-searched for relevant data. Clinical trial registries/databases and websites were also searched for relevant data. Key words were tiotropium, olodaterol, Spiolto Respimat, Stiolto Respimat, Vehelva Respimat. Records were limited to those in English language. Searches last updated 6 May 2019

Acknowledgements During the review process, the manufacturer of tiotropium/olodaterol was also offered an opportunity to review this article. Changes resulting from comments received were made on the basis of scientific and editorial merit.

\section{Compliance with Ethical Standards}

Funding The preparation of this review was not supported by any external funding.

Conflict of interest Hannah Blair is a salaried employee of Adis International Ltd/Springer Nature, is responsible for the article content and declares no relevant conflicts of interest.

Open Access This article is distributed under the terms of the Creative Commons Attribution-NonCommercial 4.0 International License (http://creativecommons.org/licenses/by-nc/4.0/), which permits any noncommercial use, duplication, adaptation, distribution and reproduction in any medium or format, as long as you give appropriate credit to the original author(s) and the source, provide a link to the Creative Commons license and indicate if changes were made.

\section{References}

1. Global Initiative for Chronic Obstructive Lung Disease. Global strategy for the diagnosis, management, and prevention of chronic obstructive pulmonary disease. 2019. http://goldcopd.org/goldreports/. Accessed 7 May 2019.

2. Boehringer Ingelheim. Stiolto ${ }^{\circledR}$ Respimat $^{\circledR}$ (tiotropium bromide and olodaterol): US prescribing information; 2018. http://www. fda.gov. Accessed 7 May 2019.

3. Pharmaceuticals and Medical Devices Agency. Spiolto Respimat 28 puffs / Spiolto Respimat 60 puffs: Japanese prescribing information; 2015. http://www.pmda.go.jp. Accessed 7 May 2019.

4. National Drug Administration Drug Evaluation Center. Tiotropium bromide olodaterol inhalation spray: Chinese prescribing information; 2018. http://202.96.26.102/. Accessed 7 May 2019.

5. European Medicines Agency. Spiolto ${ }^{\circledR}$ Respimat $^{\circledR}$ (tiotropium bromide and olodaterol): summary of product characteristics; 2018. http://www.ema.europa.eu. Accessed 7 May 2019.

6. Deeks ED. Olodaterol: a review of its use in chronic obstructive pulmonary disease. Drugs. 2015;75(6):665-73.

7. Keating GM. Tiotropium Respimat ${ }^{\circledR}$ Soft Mist ${ }^{\mathrm{TM}}$ inhaler: a review of its use in chronic obstructive pulmonary disease. Drugs. 2014;74(15):1801-16.

8. Dhillon S. Tiotropium/olodaterol: a review in COPD. Drugs. 2016;76(1):135-46.

9. Buhl R, Maltais F, Abrahams R, et al. Tiotropium and olodaterol fixed-dose combination versus mono-components in COPD (GOLD 2-4). Eur Respir J. 2015;45(4):969-79.

10. Singh D, Ferguson GT, Bolitschek J, et al. Tiotropium plus olodaterol shows clinically meaningful improvements in quality of life. Respir Med. 2015;109(10):1312-9.

11. Beeh KM, Westerman J, Kirsten AM, et al. The 24-h lung-function profile of once-daily tiotropium and olodaterol fixed-dose combination in chronic obstructive pulmonary disease. Pulm Pharmacol Ther. 2015;32:53-9.

12. Beeh KM, Derom E, Echave-Sustaeta $\mathbf{J}$, et al. The lung function profile of once-daily tiotropium and olodaterol via Respimat ${ }^{\circledR}$ is superior to that of twice-daily salmeterol and fluticasone propionate via Accuhaler ${ }^{\circledR}$ (ENERGITO ${ }^{\circledR}$ study). Int J Chron Obstruct Pulmon Dis. 2016;11(1):193-205.

13. Calverley PMA, Anzueto AR, Carter K, et al. Tiotropium and olodaterol in the prevention of chronic obstructive pulmonary disease exacerbations (DYNAGITO): a double-blind, randomised, parallel-group, active-controlled trial. Lancet Respir Med. 2018;6(5):337-44.

14. O'Donnell DE, Casaburi R, Frith P, et al. Effects of combined tiotropium/olodaterol on inspiratory capacity and exercise endurance in COPD. Eur Respir J. 2017;49(4):1601348.

15. Maltais F, O'Donnell D, Galdiz Iturri JB, et al. Effect of 12 weeks of once-daily tiotropium/olodaterol on exercise endurance during constant work-rate cycling and endurance shuttle walking in chronic obstructive pulmonary disease. Ther Adv Respir Dis. 2018;12:1-13.

16. Troosters T, Maltais F, Leidy N, et al. Effect of bronchodilation, exercise training, and behavior modification on symptoms and physical activity in chronic obstructive pulmonary disease. Am J Respir Crit Care Med. 2018;198(8):1021-32.

17. Maltais F, Aumann JL, Kirsten AM, et al. Dual bronchodilation with tiotropium/olodaterol further reduces activity-related breathlessness versus tiotropium alone in COPD. Eur Respir J. 2019. https://doi.org/10.1183/13993003.02049-2018.

18. Ferguson GT, Karpel JP, Clerisme-Beaty E, et al. Efficacy and safety of tiotropium + olodaterol maintenance treatment in patients with COPD in the TONADO ${ }^{\circledR}$ and OTEMTO ${ }^{\circledR}$ studies: a subgroup analysis by age. Int J Chron Obstruct Pulmon Dis. 2016;11(1):2701-10. 
19. Ferguson GT, Flezar M, Korn S, et al. Efficacy of tiotropium plus olodaterol in patients with chronic obstructive pulmonary disease by initial disease severity and treatment intensity: a post hoc analysis. Adv Ther. 2015;32(6):523-36.

20. Maltais F, Buhl R, Koch A, et al. $\beta$-Blockers in COPD: a cohort study from the TONADO research program. Chest. 2018;153(6):1315-25.

21. Buhl R, Derom E, Bjermer L, et al. Tiotropium + olodaterol in patients with moderate to severe COPD with chronic bronchitis and/or emphysema [abstract no. PA979]. Eur Respir J. 2016;48(Suppl 60).

22. Singh D, Gaga M, Schmidt O, et al. Effects of tiotropium + olodaterol versus tiotropium or placebo by COPD disease severity and previous treatment history in the OTEMTO ${ }^{\circledR}$ studies. Respir Res. 2016;17:73.

23. Martinez FJ, Abrahams RA, Ferguson GT, et al. Effects of baseline symptom burden on treatment response in COPD. Int J Chron Obstruct Pulmon Dis. 2019;14:181-94.

24. Derom E, Beeh KM, Echave-Sustaeta J, et al. Tiotropium + olodaterol provides significant lung-function benefits compared to flucticasone + salmeterol regardless of prior bronchodilator use [abstract no. PA978]. Eur Respir J. 2017;48(Suppl 60).

25. Ferguson GT, Karpel J, Bennett N, et al. Effect of tiotropium and olodaterol on symptoms and patient-reported outcomes in patients with COPD: results from four randomised, double-blind studies. NPJ Prim Care Respir Med. 2017;27(1):7.

26. Bai C, Ichinose $\mathrm{M}$, Lee $\mathrm{SH}$, et al. Lung function and long-term safety of tiotropium/olodaterol in East Asian patients with chronic obstructive pulmonary disease. Int J Chron Obstruct Pulmon Dis. 2017;12:3329-39.

27. Ichinose M, Taniguchi H, Takizawa A, et al. The efficacy and safety of combined tiotropium and olodaterol via the Respimat ${ }^{\circledR}$ inhaler in patients with COPD: results from the Japanese subpopulation of the Tonado ${ }^{\circledR}$ studies. Int J Chron Obstruct Pulmon Dis. 2016;11(1):2017-27.

28. Ichinose M, Nishimura M, Akimoto M, et al. Tiotropium/olodaterol versus tiotropium in Japanese patients with COPD: results from the DYNAGITO study. Int J Chron Obstruct Pulmon Dis. 2018;13:2147-56.

29. Ichinose M, Minakata Y, Motegi T, et al. Efficacy of tiotropium/ olodaterol on lung volume, exercise capacity, and physical activity. Int J Chron Obstruct Pulmon Dis. 2018;13:1407-19.

30. Minakata Y, Motegi T, Ueki J, et al. Efficacy of tiotropium/olodaterol on sedentary/active time in COPD patients: VESUTO study [abstract no. PA4390]. Eur Respir J. 2018;52(Suppl 62).

31. Feldman GJ, Sousa AR, Lipson DA, et al. Comparative efficacy of once-daily umeclidinium/vilanterol and tiotropium/olodaterol therapy in symptomatic chronic obstructive pulmonary disease: a randomized study. Adv Ther. 2017;34(11):2518-33.

32. Valipour A, Tamm M, Kocianova J, et al. Improvement of selfreported physical functioning with tiotropium/olodaterol in Central and Eastern European COPD patients [abstract no. PA912]. Eur Respir J. 2018;52.

33. Buhl R, Magder S, Bothner U, et al. Long-term general and cardiovascular safety of tiotropium/olodaterol in patients with moderate to very severe chronic obstructive pulmonary disease. Respir Med. 2017;122:58-66.

34. Ferguson GT, Buhl R, Bothner U, et al. Safety of tiotropium/olodaterol in chronic obstructive pulmonary disease: pooled analysis of three large, 52-week, randomized clinical trials. Respir Med. 2018;143:67-73.

35. Ichinose M, Kato M, Takizawa A, et al. Long-term safety and efficacy of combined tiotropium and olodaterol in Japanese patients with chronic obstructive pulmonary disease. Respir Investig. 2017:55(2):121-9.
36. Singh D. New combination bronchodilators for chronic obstructive pulmonary disease: current evidence and future perspectives. $\mathrm{Br}$ J Clin Pharmacol. 2015;79(5):695-708.

37. Calzetta L, Rogliani P, Matera MG, et al. A systematic review with meta-analysis of dual bronchodilation with LAMA/LABA for the treatment of stable COPD. Chest. 2016;149(5):1181-96.

38. Schlueter M, Gonzalez-Rojas N, Baldwin M, et al. Comparative efficacy of fixed-dose combinations of long-acting muscarinic antagonists and long-acting beta2-agonists: a systematic review and network meta-analysis. Ther Adv Respir Dis. 2016;10(2):89-104.

39. Sion KYJ, Huisman EL, Punekar YS, et al. A network metaanalysis of long-acting muscarinic antagonist (LAMA) and longacting $\beta_{2}$-agonist (LABA) combinations in COPD. Pulm Ther. 2017:3:297-316.

40. Rogliani P, Matera MG, Ora J, et al. The impact of dual bronchodilation on cardiovascular serious adverse events and mortality in COPD: a quantitative synthesis. Int J Chron Obstruct Pulmon Dis. 2017;12:3469-85.

41. Molimard M, Raherison C, Lignot S, et al. Chronic obstructive pulmonary disease exacerbation and inhaler device handling: real-life assessment of 2935 patients. Eur Respir J. 2017;49(2): 1601794.

42. Dalby RN, Eicher J, Zierenberg B. Development of Respimat ${ }^{\circledR}$ Soft Mist ${ }^{\mathrm{TM}}$ Inhaler and its clinical utility in respiratory disorders. Med Devices (Auckl). 2011;4:145-55.

43. Dekhuijzen PN, Lavorini F, Usmani OS. Patients' perspectives and preferences in the choice of inhalers: the case for Respimat ${ }^{\circledR}$ or HandiHaler $^{\circledR}$. Patient Prefer Adherence. 2016;10:1561-72.

44. Oliveira MVC, Pizzichini E, da Costa $\mathrm{CH}$, et al. Evaluation of the preference, satisfaction and correct use of Breezhaler ${ }^{\circledR}$ and Respimat ${ }^{\circledR}$ inhalers in patients with chronic obstructive pulmonary disease-INHALATOR study. Respir Med. 2018;144:61-7.

45. Asakura Y, Nishimura N, Maezawa K, et al. Effect of switching tiotropium HandiHaler ${ }^{\circledR}$ to Respimat ${ }^{\circledR}$ Soft Mist Inhaler in patients with COPD: the difference of adverse events and usability between inhaler devices. J Aerosol Med Pulm Drug Deliv. 2013;26(1):41-5.

46. Miravitlles M, Montero-Caballero J, Richard F, et al. A crosssectional study to assess inhalation device handling and patient satisfaction in COPD. Int $\mathrm{J}$ Chron Obstruct Pulmon Dis. 2016;11:407-15.

47. Dhand R, Eicher J, Hansel M, et al. Improving usability and maintaining performance: human-factor and aerosol-performance studies evaluating the new reusable Respimat inhaler. Int J Chron Obstruct Pulmon Dis. 2019;14:509-23.

48. Tebboth A, Ternouth A, Gonzalez-Rojas N. UK-specific costeffectiveness of tiotropium + olodaterol fixed-dose combination versus other LAMA + LABA combinations in patients with COPD. Clinicoecon Outcomes Res. 2016;8:667-74.

49. Hoogendoorn M, Corro Ramos I, Baldwin M, et al. Long-term cost-effectiveness of the fixed-dose combination of tiotropium plus olodaterol based on the DYNAGITO trial results. Int J Chron Obstruct Pulmon Dis. 2019;14:447-56.

50. Selya-Hammer C, Gonzalez-Rojas Guix N, Baldwin M, et al. Development of an enhanced health-economic model and costeffectiveness analysis of tiotropium + olodaterol Respimat ${ }^{\circledR}$ fixed-dose combination for chronic obstructive pulmonary disease patients in Italy. Ther Adv Respir Dis. 2016;10(5):391-401.

51. van Boven JF, Kocks JW, Postma MJ. Cost-effectiveness and budget impact of the fixed-dose dual bronchodilator combination tiotropium-olodaterol for patients with COPD in the Netherlands. Int J Chron Obstruct Pulmon Dis. 2016;11(1):2191-201. 